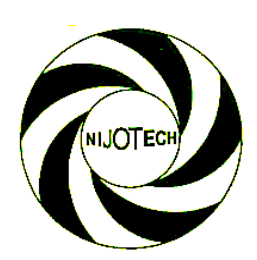

Nigerian Journal of Technology (NIJOTECH)

Vol. 38, No. 2, April 2019, pp. 315 - 325

Copyright@ Faculty of Engineering, University of Nigeria, Nsukka,

Print ISSN: 0331-8443, Electronic ISSN: 2467-8821 www.nijotech.com

http://dx.doi.org/10.4314/njt.v38i2.7

\title{
MECHANICAL PROPERTIES OF ALUMINUM FOAM REINFORCED WITH RECYCLED CERAMIC AGGREGATES
}

\author{
C. A. Ajoku* \\ Department of Civil Engineering, Federal University of TeChnology OWerRi, Imo StATE, NIGERIA \\ E-mail address: chinedu.ajoku@futo.edu.ng
}

\begin{abstract}
This research work investigates the mechanical properties of two distinct novel composites of aluminum foam made from the addition of recycled ballistic aggregates to the foams of aluminum alloy powder in regular and random patterns through powder metallurgy process. The mechanical attributes of these composites were examined in compression loading using digital image correlation (DIC) and compared to baseline properties of steel and aluminum foams obtained in the laboratory and literature respectively. The results obtained for aluminum foam ceramic composite made through the dispersion of ceramic aggregates in regular orientation showed an increase in its plateau stress, yield strength, strength/density ratio and relative density, but a decrease in its modulus of elasticity was observed. This observation was similar to the composite with a random arrangement of ceramic aggregates, except for a decrease noticed in its yield strength and elastic modulus.
\end{abstract}

Keywords: Aluminum Alloy Powder, Digital Image Correlation, Mechanical Properties, Novel Composites, Powder Metallurgy, Recycled Ballistic Aggregates.

\section{INTRODUCTION}

Aluminum foam is a form of porous metallic foam with excellent thermal, electrical, mechanical and acoustic properties, which are widely used in various engineering applications [1]. Notwithstanding its wide uses in several engineering designs, its properties are usually affected by variation in pore sizes. Because of non-uniformity of their internal cell structures, collapse bands do initiate in unpredictable locations, which leads to poor performances during their service life [2, 3].

In order to enhance the effectiveness of aluminum foams for the purposes they are designed for, materials such as ceramic, polymer and solid metals are added in the course of their production. In situations where ceramic aggregates are used to reinforce the metallic foams (that is, during the process of microstructural modification) to produce a more uniform cell structure, the resulting composites are referred to as metal matrix syntactic foams.

Powder metallurgy and casting technique are the two commonly used methods of producing composites of metallic foams $[4,5]$. Casting technique is used where two distinct materials with different melting points are involved, for example, the production of composite metal foams using aluminum metal base and pre-form hollow steel spheres. However, when two materials with similar melting points (that is, steel powder and spherical hollow steel) are used to produce the composites, powder metallurgy method is utilized. The advantage of this process is that it is used to make composites with stronger bonding and lower defects at points of interconnections (or interface).

Many research works have focused extensively on the mechanical properties and useful applications of metal matrix syntactic foams made with cenosphere/microballoons, which are known as ceramic particles realized from fly ash [6 - 8]. In order to ensure uniformity in the microstructural arrangement of metal foams, these ceramic inclusions/ aggregates are introduced during the foaming of metallic alloys or base metals so as to create the space holding effect.

*Author, tel: $+234-703-388-8065$ 
Mondal, et al. [7] investigated the properties of aluminum matrix syntactic foam made by casting techniques, which involves mechanical stirring of preheated particles of cenospheres and molten aluminum alloy at a pressure of $1-3 \mathrm{MPa}$ on a die assembly. They observed five stages of the stressstrain graph when the resulting composites were tested under uniaxial compression loading. These are; elastic stage/region, yielding region, well-defined yield point, a plateau region and densification stage. Similarly, Wu et al. [8] examined the behaviour of cenosphere-pure aluminum syntactic foams when loaded under quasi-static compression. The research reported a steady rise in stress after the plateau stage. This behaviour, they attributed to the absorption of energy during the densification of the cenospherealuminum syntactic foams. Orbulov et al. [6], on the other hand, obtained a direct relationship between fatigue strengths of metal matrix syntactic foam and their compressive strengths which were necessary for understanding their behaviour during service life.

Recently, there is a growing need to expand the applications of metal matrix syntactic foams to further provide lightweight protection to cut, drill and ballistic threats, which are all typical examples of forcible entry attacks. Therefore, the concept adopted by this research to achieve this was to wholly replace the conventional cenosphere/microballoons ceramic particles with recycled ALOTEC-99SB alumina (ballistic armour tiles), which are stronger and tougher than the conventional materials.

Thus, the main aim of this research work is to determine the mechanical properties of two novel composites of aluminium foam in compression, which are produced by simply altering the orientation of the recycled ceramic aggregates in the cells of aluminium foam. These mechanical properties obtained from the data acquisition systems of digital image correlation (DIC) and universal testing machine will be compared to those of trial steel foam specimens and baselines from previous research works in order to draw relevant conclusions.

\section{MATERIALS AND METHODS}

\subsection{Materials}

In this research, the materials used include; recycled ceramic armour tiles, nickel-chromium wire, aluminium alloy powder and titanium hydride (foaming agent).

The recycled ballistic tiles (also known as ALOTEC99SB) were purchased from Ceram Tec. They are ivory in colour and are products of aluminum oxide powder, manufactured by pressure-less fritting. The shape of this tile is regular hexagon of thickness $4 \mathrm{~mm}$ and side length $10 \mathrm{~mm}$. Its material properties are as follows: open porosity of $0 \%$ equivalent to DIN EN 623-2 minimum standard, sound velocity $(10.644 \mathrm{~m} / \mathrm{s})$ greater than ASTM-E-494 minimum standard, hardness $\left(1727 \mathrm{~kg} / \mathrm{mm}^{2}\right)$ greater than DIN EN $843-4$ minimum standard, density $\left(3.92 \mathrm{~g} / \mathrm{cm}^{3}\right)$ greater than DIN EN 623-2 minimum standard and $\mathrm{Al}_{2} \mathrm{O}_{3}$-content $(>99.7 \%)$. The choice of this ceramic armour reject was influenced by the need to minimise cost and ensure sustainability of our environment in the manufacture of protective systems for forcible entry threat resistance.

Nickel Chromium wire is an alloy wire with a melting point in the range of $1200^{\circ} \mathrm{C}-1400^{\circ} \mathrm{C}$ when heated. The wire which has a diameter of $0.5 \mathrm{~mm}$ was purchased from eBay. Aluminum silicon alloy powder with a melting point in the range of $590^{\circ} \mathrm{C}-750^{\circ} \mathrm{C}$ was chosen as the base metal for the composite aluminum foams. This alloy powder is characterised by high strength, exceptional thermal conductivity, very low weight and less significant coefficient of thermal expansion. It has a silver-grey colour. Titanium hydride regarded as the foaming agent in the powder metallurgy process has an approximate melting point of $450^{\circ} \mathrm{C}$. It is usually available in commercial quantity at an average density of $3.76 \mathrm{~g} / \mathrm{cm}^{3}$, in either black or grey powder form. This material does not exhibit any form of a chemical reaction with water.

\subsection{Methods}

\subsubsection{Pairs of Recycled Ceramic Aggregate for Cylindrical Specimens}

Pairs of ceramic aggregates were produced manually using protective hand gloves, $30 \mathrm{~cm}$ metre rule and sets of pliers. This stage involves tying of two pieces of aggregates with nichrome wire of $0.5 \mathrm{~mm}$ diameter in order to produce multiples of interconnected tiles for the cylindrical specimens.

\subsubsection{Powder Metallurgy Process for Production of Aluminum Foams with Ceramic Inclusions}

The composites of aluminum foam were manufactured at Fraunhofer Institute of Advanced Materials (IFAM) by powder metallurgy process. There are five stages involved in this process, which are; mixing, compacting, extrusion, foaming and cooling. In the mixing stage, a tumbling mixer was used to thoroughly blend the aluminum silicon alloy powder and the 
titanium hydride to produce a homogenous mixture. This blended mix is compressed in a die and extruded to form precursor materials at a predefined tubular force. Finally, these precursor materials and ceramic aggregates are put in a metallic cylindrical mould of height/diameter ratio of 2.5 (that is, diameter $60 \mathrm{~mm}$, and height $150 \mathrm{~mm}$ ) and heated at a temperature above $750^{\circ} \mathrm{C}$ to form aluminum foam composites. Two types of aluminum foam composites were produced by changing the orientation of the ceramic inclusions in the mould before heating. They are sample Aaluminum foam ceramic composite which has ceramic aggregates stacked in a regular pattern and sample Baluminum foam ceramic composite which has ceramic aggregates stacked in random orientation. Sample A has a measured density of $1.037 \mathrm{~g} / \mathrm{cm}^{3}$ while the density of sample $B$ is $0.899 \mathrm{~g} / \mathrm{cm}^{3}$. They are shown in Figure 1.

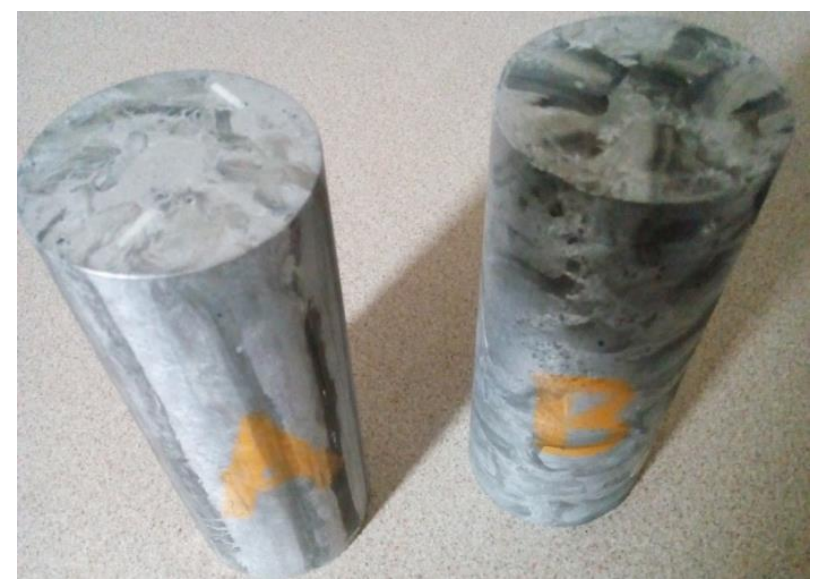

Figure 1: Aluminum Foam Composites manufactured by Powder Metallurgy (a) Aluminum foam Composite which has Ceramic Aggregates stacked in regular orientation (b) Aluminum foam Composite which has Ceramic Aggregates stacked in random orientation

\subsubsection{Steel foam baseline specimens}

Three trial specimens measuring $30 \times 30 \times 50 \mathrm{~mm}$ shown in Figure 2 were cut from $55 \times 55 \times 220 \mathrm{~mm}$ parent steel foam procured from Fraunhofer Institute of Advanced Materials (IFAM), Dresden, Germany. With the aid of Equation 1, given by Salmon et al. [9], it was confirmed that these cut specimens will not buckle under the action of quasi-static compression load. These trial specimens are necessary for the experimental set-up, which involves synchronising the digital image correlation (DIC) software with the data collection point for the Instron compression machine.

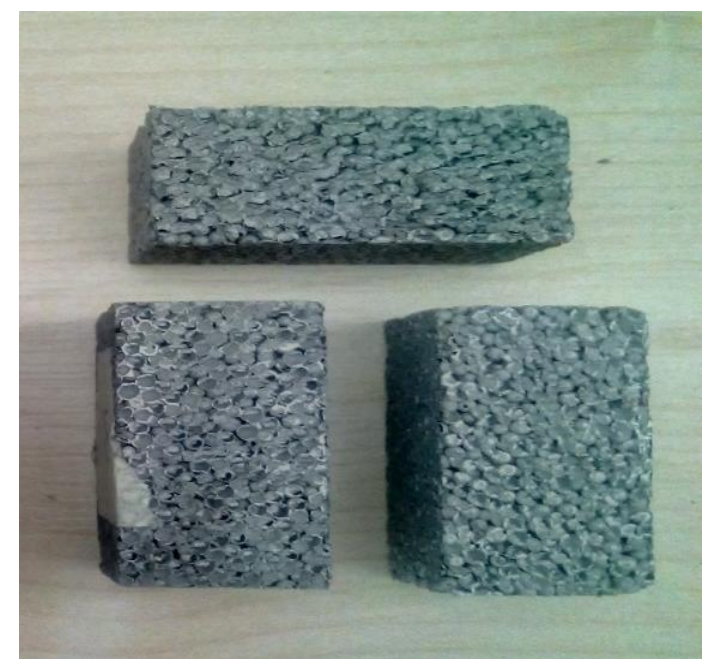

Figure 2: Three trial Specimens of Steel Foam Measuring $30 \times 30 \times 50 \mathrm{~mm}$

The results obtained from these trials would also help provide further explanations of the behaviour of the novel aluminum foam composites produced in this research.

$$
F_{c r}=F_{y}\left[1-\left(\frac{F_{y}}{4 \pi^{2} E}\right)\left(\frac{K L}{r}\right)^{2}\right]
$$

Where, $F_{c r}=$ critical buckling stress, $F_{y}=$ yield stress, $\mathrm{E}=$ modulus of elasticity of metallic foams and $\mathrm{KL} / \mathrm{r}=$ slenderness ratio.

\subsubsection{Application of digital image correlation (DIC) in compression test of metallic foams}

In order to successfully apply DIC in extracting the properties of metallic foam materials, four important steps are observed. These four processes are; i) preparation of specimen, ii) set-up for the set of cameras, iii) calibration of the set of cameras, and iv) selection of best speckle pattern using Sigma plot.

Specimen preparation for DIC involves applying a speckle pattern on the surface area within the view of the two cameras. This is usually done to assist in tracking the variation in the contour/deformation of subset images by the camera. Setting-up the cameras involves the following; mounting and positioning the two cameras (using sets of turnkey drivers) on the aluminum profile attached to the tripod stand, pointing the two cameras at an angle of view of $15^{\circ}$ to $45^{\circ}$ to the target specimen and fine-tuning the focus of the cameras to obtain clear view of the object. At this stage, an adequate light source was used to ensure proper illumination of the specimens, and this was done such that reflection which causes the oversaturation of images visible on Vic-Snap was totally avoided. DIC camera calibration involves placing the calibration boards in the same position 
where the specimens are placed during the experiment. Two calibration boards of $7 \mathrm{~mm}$ and $10 \mathrm{~mm}$ size were used due to the range of sizes of the specimens to be tested. Images of these boards at 30 different orientations (that is, horizontal rotations, vertical rotations and in-plane/random orientation) were captured using the Vic-Snap component of the DIC. Then, the software was switched to Vic-3D so as to determine the calibration scores for the boards. Calibration scores of 0.035 (as shown in Figure 3) and 0.028 were obtained for $7 \mathrm{~mm}$ and $10 \mathrm{~mm}$ size boards respectively, and these were less than 0.05 maximum allowable standard error. The sigma plot function of Vic 3D was used to analyse different speckle patterns for selection of an appropriate pattern which would yield accurate results. In this experiment, due to the texture of the specimens and the results from sigma plot, black and white speckle pattern was chosen.

\subsubsection{Compression test}

Instron 5982 with a capacity of $100 \mathrm{KN}$ which has a data acquisition system was used to carry out the compression tests for all the specimens at a room temperature of $28^{\circ} \mathrm{C}$. The data acquisition systems for the Instron machine and DIC were both synchronised to ensure material property changes recorded on the DIC match accurately to the corresponding forces (on the compression machine) causing such effects. All the specimens were concentrically positioned on the circular platen of the Instron machine and loaded to failure in accordance with BS ISO 13314 at a crosshead displacement velocity of $1 \mathrm{~mm} / \mathrm{min}$. This loading rate was chosen to allow the data acquisition system of DIC (that is, Vic-Snap and Vic-3D) to acquire detailed data for further analysis.

\subsection{RESULTS AND DISCUSSION}

\subsection{Mechanical Properties from Compression Test}

Figure 4 represents the stress-strain curves from the cross-head displacement of Instron machine for steel foam specimens $2 \mathrm{~A}, 2 \mathrm{~B}$ and $2 \mathrm{C}$. As expected of a typical metal foam undergoing uniaxial compression, three stages of deformation are illustrated on the curve. They are linear elastic region, plastic yielding plateau region (known for its constantly close gradient) and the densification or final hardening region. The stress-strain curve was derived from the load-extension values given by the universal testing machine. An approximate densification strain of $55 \%$ is observed for specimens $2 \mathrm{~A}$ and $2 \mathrm{~B}$.

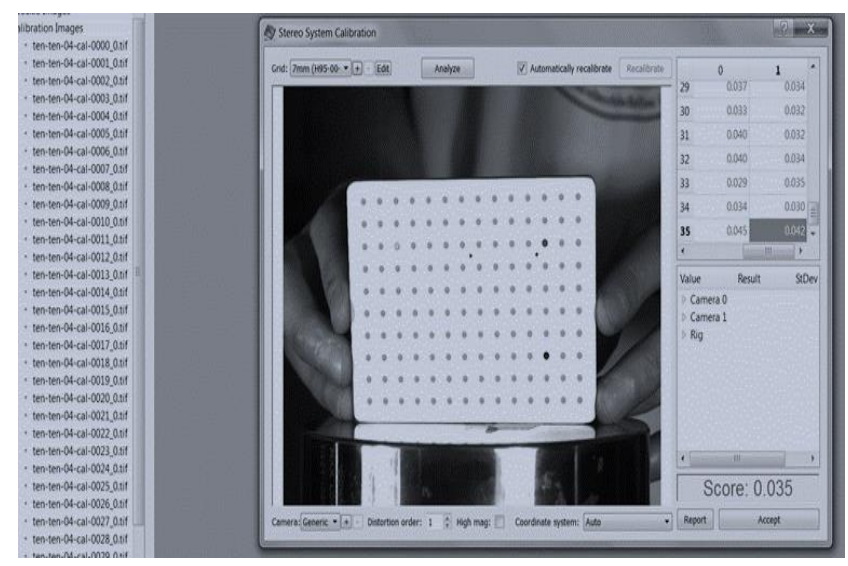

Figure 3: Reading of Calibration Score in Vic-3D Environment for $7 \mathrm{~mm}$ Board

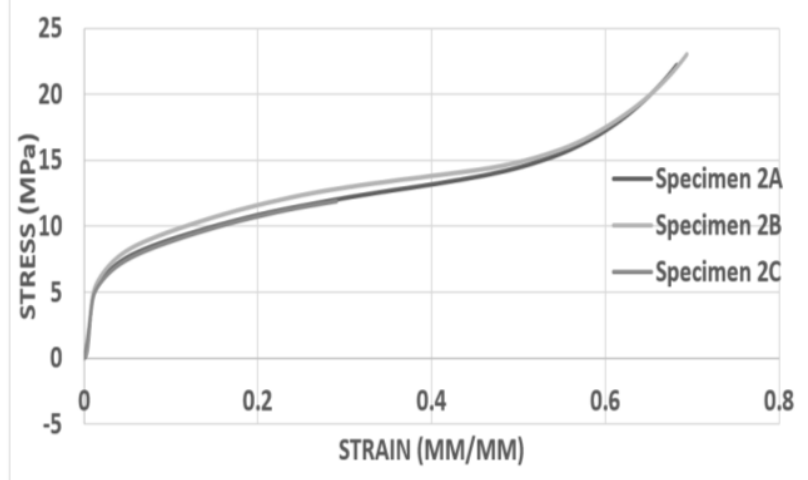

Figure 4: Stress-strain Curve of Hollow Steel Foam Trial Specimens

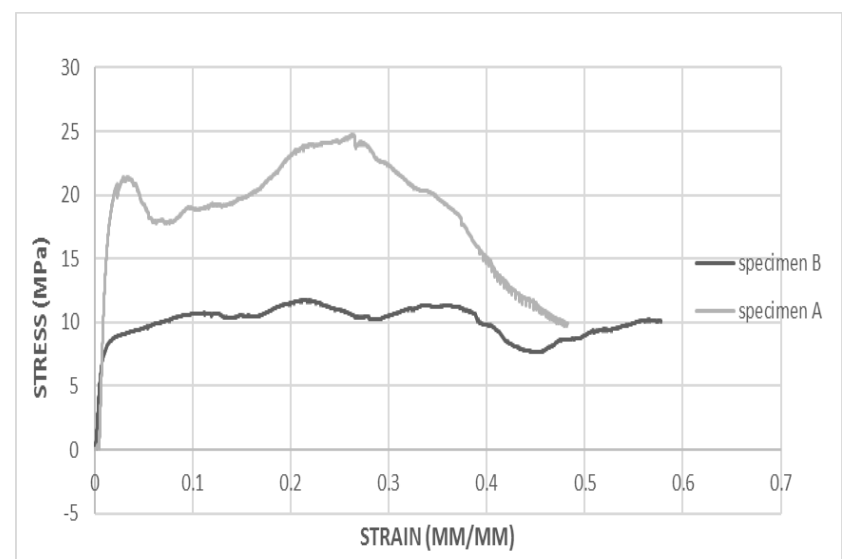

Figure 5: Stress-strain Curve of Aluminum Foam Ceramic Composites

However, the compression experiment on specimen $2 \mathrm{C}$ was terminated at $29 \%$ strain because of excessive disturbance in the results realised from the DIC data acquisition system.

Figure 5, on the other hand, represents the stressstrain relationships for the two types of aluminum foam composite tested in the laboratory at room temperature. Whereas specimen A shows the aluminum foam composite which has ceramic 
aggregates regularly arranged in its cell structure, specimen B depicts the composite with ceramic inclusions arbitrarily placed in its internal structure. Both specimens seem to exhibit different behavior under compression load. While specimen $A$ tends to behave like a solid steel loaded in tension, specimen $B$ follows the typical behavior of aluminum foams in quasi-static compression.

From Figures 4 and 5, the values of yield stress, plateau stress, densification strain, densification stress, strength/density ratio, energy absorption and modulus of elasticity were estimated for the steel foam and aluminum foam ceramic composites. These values are presented in Table 1 along with baseline results from previous research works.

Figure 6 presents the relationship between Poisson's ratio and longitudinal strain for the trial steel foam specimens, which was derived from the DIC data collection point. It can be observed from the plot that the Poisson's ratio value for the material starts from 0 and reaches the value of 0.14 at $1 \%$ strain. A steady value of 0.12 was observed between strain values of $10 \%$ and $15 \%$, which then rises to 0.15 when the experiment was stopped at $25 \%$ strain. Thus, the Poisson's ratio value of the trial steel foam is said to be in the range of $0-0.13$.

Figure 7 represents the relationships between Poisson's ratio and average axial strains for specimens $A$ and B. Specimen B has a Poisson's ratio-axial strain curve which originates from 0 and rises to 0.18 at $0.2 \%$ average longitudinal strain, and then experiences another rise to a steady value of 0.2 at $8 \%$ strain. Therefore, its Poisson's ratio ranges from 0-0.2 within $8 \%$ compression strain. However, the Poisson's ratio-axial strain curve of specimen A shows a wide variation in value and falls in the range of 0 0.32 akin to the Poisson's ratio values of solid steel given as $0.31-0.32$.

\subsubsection{Compressive/Yield Strength}

The relative densities of aluminum foam composites produced in this research are higher than those of ordinary aluminum and steel foams given in Table 1 . These results show that the addition of ceramic aggregates to metallic foams means an increase in density, which positively affects the relative density. Because of the direct relationship which exists between relative density and yield strength, this would mean a resultant increase in the compressive/yield strengths of the composites when compared to their metallic foams without ceramic inclusions.

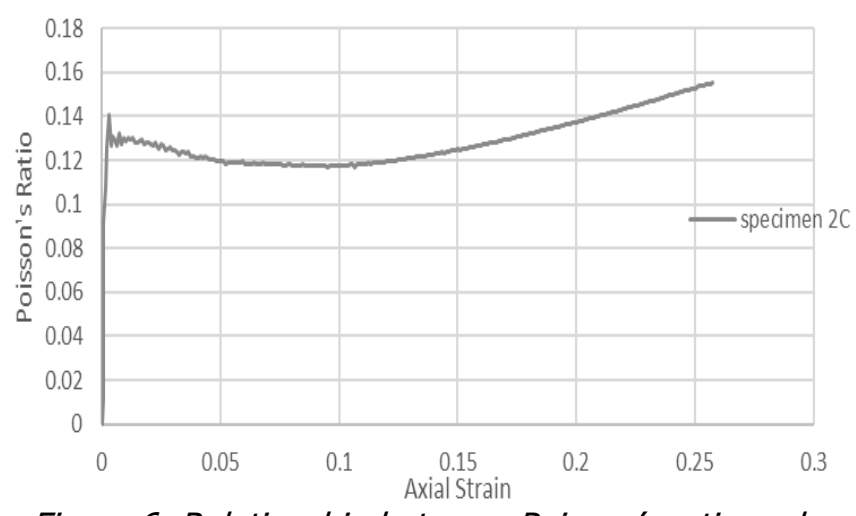

Figure 6: Relationship between Poisson's ratio and average longitudinal strain for steel foam

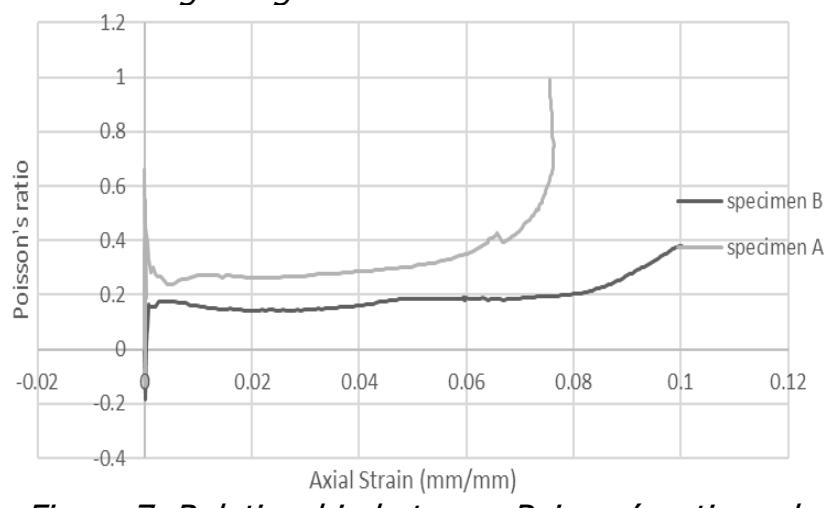

Figure 7: Relationship between Poisson's ratio and average longitudinal strain for Aluminum Foam Composites

As observed from Table 1, the aluminum foam ceramic composite with a regular arrangement of ceramic tiles in its internal structure has a yield strength of $22 \mathrm{MPa}$, which is higher than the values provided by Xia et al. [11] and [12] and falls in the range given by Fraunhofer, IFAM [10]. However, the yield strength of 8.6MPa was observed for the aluminum foam ceramic composite which ceramic aggregates randomly distributed in its internal cell structure. This value of yield strength is very close to the values obtained by Xia et al. [11] for aluminum foam composites produced from microsphere particles.

\subsubsection{Strength/Density Ratio}

This is an important engineering property which indicates the ability of engineering materials to withstand applied stresses at low densities. Strength/density ratio is obtained by dividing the plateau stress of a material by its measured density. From Table 1, the value of 11.5MPa was obtained as the plateau stress for both hollow steel foam and aluminum foam composite with the irregular stacking of ceramic tiles, even when their behaviour on the stress-strain graphs (shown in Figures 4 and 5) differ from each other. The hollow steel foam produced a 
smooth stress-strain curve under compression load while that of aluminum foam composite undulates at an approximate interval of $10 \%$ strain. A short plateau stage was observed for aluminum composite with the regular orientation of ceramic tiles, which gave a value of $19 \mathrm{MPa}$ and $17.76 \mathrm{MPa} . \mathrm{cm}^{3} / \mathrm{g}$ as plateau stress and strength/density ratio respectively. These values are higher than those of previous researches given in Table 1. Also, the behaviour of this material, shown in Figure 5, is similar to that of a solid metal under a tension load. Therefore, this material is said to exhibit compressive ductility under crushing load.

\subsubsection{Energy Absorption Capacity}

The two forms of aluminum foam composites made in this research have greater values of energy absorption capacity than those of ordinary aluminum foam given by Fraunhofer, IFAM [10] and Xia et al. [12] as $3.1 \mathrm{MJ} / \mathrm{m}^{3}$ and $3.75 \mathrm{MJ} / \mathrm{m}^{3}$ respectively as shown in Table 1. What this implies is that the addition of ceramic aggregates to aluminum foams positively contributes to their energy absorption capacity. However, the same interpretation cannot be made about their energy absorption efficiency. This is because as seen in Table 1, the value of energy absorption efficiency of $78.9 \%$ obtained in this research for aluminum foam composite (which has the arrangement of ballistic tiles in regular pattern in its cell structure) falls in the range of $75.3-85 \%$ for ordinary aluminum foams provided by Fraunhofer Institute of Advanced Materials. The value of $104.4 \%$ was estimated as the energy absorption efficiency for aluminum composite with irregular structures of ceramic aggregates, depicting the effect of orientation of the ceramic ballistic tiles on the mechanical properties of composites of aluminum foam. Therefore, the high values of energy absorption capacity and efficiency calculated for these new materials mean they could successfully be deployed as crashworthy material in engineering designs which require good compressibility.

\subsubsection{Modulus of Elasticity}

Modulus of elasticity is the measure of the stiffness of a material, which directly relates to its ability to stop fast moving projectiles. This means that the higher the value of elastic modulus of a material, the greater its usefulness in the design of protective systems. From the values of elastic modulus determined in Table 1, it can be observed that the aluminum foam composites manufactured in this research have lower values when compared to the range predicted by Fraunhofer, IFAM
[10], contrary to what is obtainable for other forms of aluminum foam composites made by previous research work [6]. A likely explanation for this behaviour may be due to the improper bonding of aluminum matrix and ceramic aggregates in the heating and cooling (foaming) stage during powder metallurgy process, leading to imperfections (that is, presence of large pores) and anisotropy in the cell structures of the composites, which negatively affect elastic modulus.

\subsubsection{Poisson's Ratio}

With the aid of data acquisition software of DIC, it is possible to obtain the values of longitudinal/axial strains, transverse strains and shear strains from the compression test experiment. The value of Poisson's ratio, therefore, is calculated as the ratio of transverse strain to the axial strain. Poisson's ratio is an engineering property which measures the ability of a material to either compress or expand in the direction to which load is applied to it. From Table 1, Poisson's ratio values of $0-0.20$ and $0-0.32$ were estimated for aluminum foam composites having a random and regular arrangement of ballistic tiles respectively, within $7 \%$ compression strain (see Figure 7). These values are greater than that of steel foam gotten in this research (see Figure 6), obviously due to the relative difficulty experienced by the Instron machine in crushing the aluminum foam composites tubes. The determination of Poisson's ratio was limited to 7\% strain as a result of a loss in data (that is, axial and transverse strains) observed in Vic-3D data collection point of the DIC. An explanation for the dearth in data is that the in-folding/decrease in the height of the specimens during compression loading result to the disappearance of speckle patterns (or sigma plots), which are read and interpreted as numeric values to mark the changes in the size of the specimens. Also, this loss in data could as well have been caused by vibrations of the metallic foams due to the loading rate. In other words, the higher the rate of loading of samples of metal foams and their composites, the less accurate the results that would be extracted from the DIC data acquisition system. It is vital to state that aluminum foam composite with higher Poisson's ratio values (sample A) exhibited orthotropic behaviour (that is, nonhomogeneous deformation/shearing) beyond $10 \%$ strain, meaning that the axial compression of this material never passed through the axis of loading noticeable in other metallic foams tested (see Figure 9a). 
Table 1: Mechanical Properties of Aluminum Foam Ceramic Composites and Other Metal Foams Under QuasiStatic Compression Load

\begin{tabular}{|c|c|c|c|c|c|c|}
\hline Mechanical properties & $\begin{array}{l}\text { Al Foam } \\
{[10]}\end{array}$ & $\begin{array}{l}\text { Al } \\
\text { Microsphere } \\
\text { Foam [11] }\end{array}$ & $\begin{array}{l}\text { Closed } \\
\text { Cell Al } \\
\text { Foam [12] }\end{array}$ & $\begin{array}{l}\text { Hollow Steel } \\
\text { Foams (from } \\
\text { experiment) }\end{array}$ & $\begin{array}{l}\text { Al Foam } \\
\text { Composite- } \\
\text { Regular Structure } \\
\text { (Specimen A) }\end{array}$ & $\begin{array}{l}\text { Al Foam } \\
\text { Composite- } \\
\text { Random Structure } \\
\text { (Specimen B) }\end{array}$ \\
\hline Density $\left(\mathrm{g} / \mathrm{cm}^{3}\right)$ & $0.5-0.8$ & 0.8 & 0.54 & 1.124 & 1.037 & 0.899 \\
\hline Relative density & $\begin{array}{l}0.186- \\
0.3\end{array}$ & 0.3 & 0.202 & 0.145 & 0.381 & 0.331 \\
\hline Yield Stress (MPa) & $11.1-29$ & 8.02 & 1.53 & 4.2 & 22 & 8.6 \\
\hline plateau stress (MPa) & $\begin{array}{l}8.5(20- \\
30 \% \\
\text { Strain) }\end{array}$ & $\begin{array}{l}10(5-55 \% \\
\text { strain) }\end{array}$ & $\begin{array}{l}7(5-55 \% \\
\text { strain) }\end{array}$ & $\begin{array}{l}11.5(20-30 \% \\
\text { strain) }\end{array}$ & $\begin{array}{l}19 \text { (short plateau } \\
\text { stage) }\end{array}$ & $\begin{array}{l}11.5(20-30 \% \\
\text { Strain) }\end{array}$ \\
\hline Densification Strain (\%) & $40-78$ & 55 & 65 & 55 & 26 & $>60$ \\
\hline $\begin{array}{l}\text { Densification stress } \\
\text { (MPa) }\end{array}$ & $8.0-20$ & 15 & 4 & 16 & 25 & $>10$ \\
\hline $\begin{array}{l}\text { Strength/Density ratio } \\
\left(\mathrm{MPa} . \mathrm{cm}^{3} / \mathrm{g}\right)\end{array}$ & $10.6-17$ & 12.5 & 13 & 10.23 & 17.76 & 12.79 \\
\hline $\begin{array}{l}\text { Energy absorbed at } 50 \% \\
\text { strain }\left(\mathrm{MJ} / \mathrm{m}^{3}\right)\end{array}$ & 3.1 & 4 & 3.75 & 5.23 & 5.13 (26\% strain) & 4.7 \\
\hline $\begin{array}{l}\text { Energy absorption } \\
\text { efficiency }(\%)\end{array}$ & $75.3-85$ & 49 & 144 & 70 & 78.9 & 104.4 \\
\hline Elastic modulus (MPa) & $\begin{array}{l}3500- \\
8400\end{array}$ & - & - & 3250 & 2000 & 1670 \\
\hline Poisson's Ratio & _- & _- & _- & $0-0.13$ & $0-0.32$ & $0-0.20$ \\
\hline
\end{tabular}

*Al= Aluminum

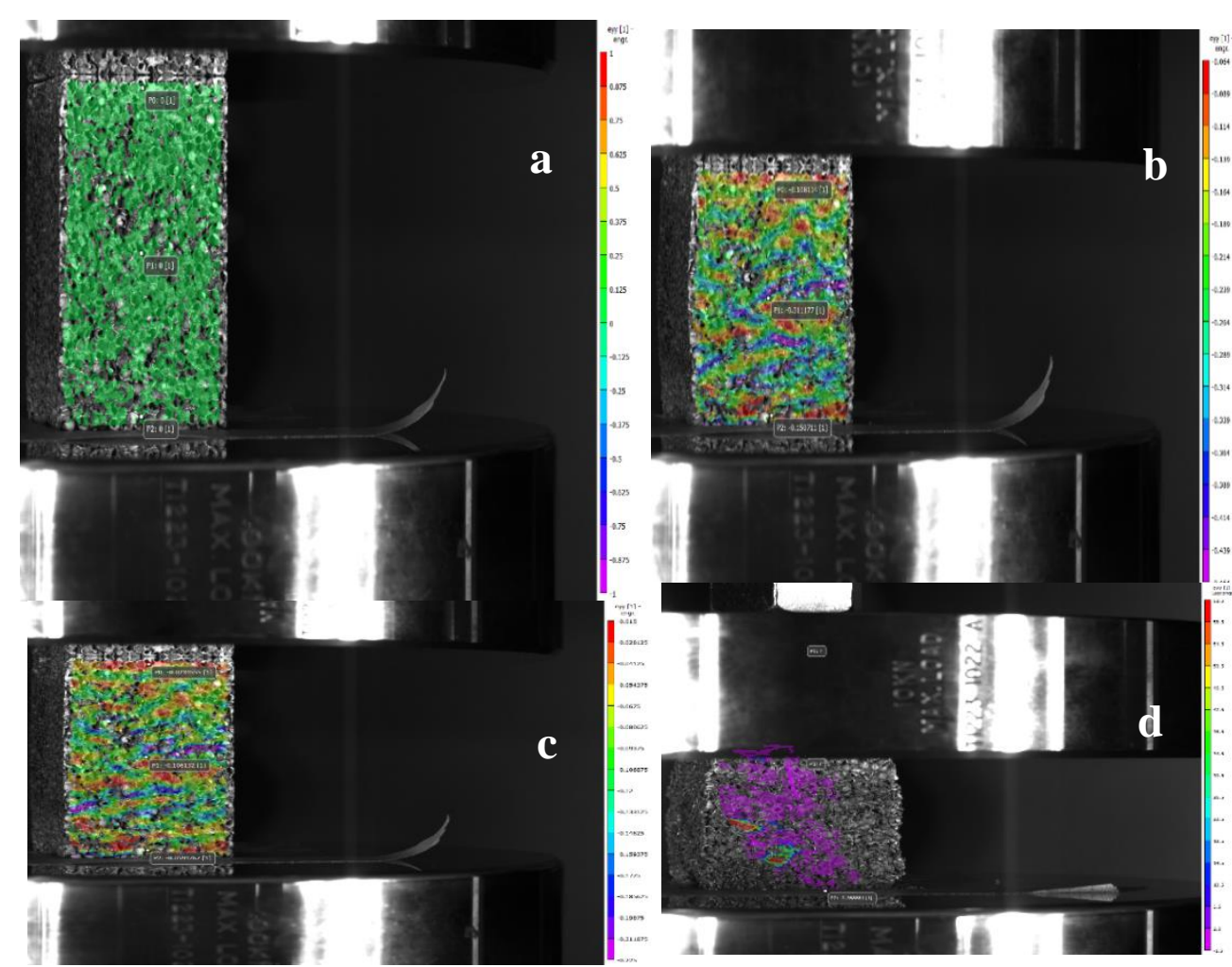

Figure 8: Gradual Failure of Steel Foam under Uniaxial Compression loading at (a) $0 \%$ strain (b) $10 \%$ strain (c) $25 \%$ strain (d) $50 \%$ strain 


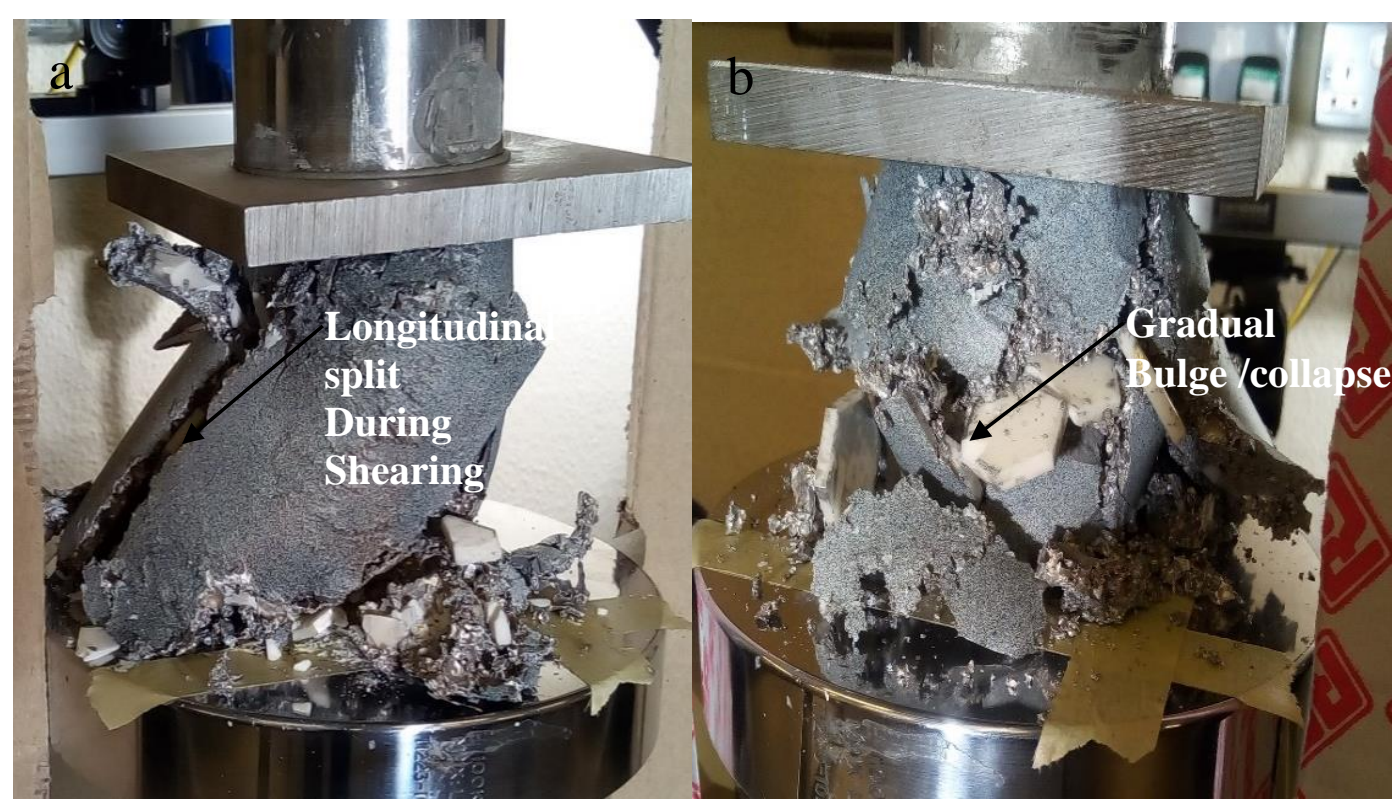

Figure 9: Mode of Failure of a) Specimen $A$ and b) Specimen B in Compression Loading

\subsection{Failure of Steel Foams and Aluminum Foam Composites under Compression Load}

Figure 8 demonstrates the form of failure typical of hollow steel foam obtained from Fraunhofer Institute of Advanced Material for 0-50\% strain when subjected to a compression load. From the figure, it can be observed that the material failure started by inward movement of the foam structure which progressed to obvious shearing and outward buckling of the foam specimen as the loading is increased.

Figure 9, on the other hand, shows the final failure modes of the two types of aluminum foam composites produced in this research. Specimen A, identified as aluminum foam which has ceramic inclusions arranged in a regular pattern failed by longitudinal split and shearing, while specimen $B$, known as aluminum foam with irregular or random orientation of ceramic tiles in its structural configuration failed by inward and outward movement of its cellular structure and protective skin respectively. This form of failure identified in specimen $B$ is typical of aluminum foams.

\subsection{Effect of Directional Orientation of Ceramic Aggregates in Aluminum Foam}

This research has exposed the relevance of orientation/arrangement of ceramic aggregates to the mechanical properties of composites of aluminum foams. Having this vital knowledge means that the final characteristics of aluminum foam ceramic composites can be influenced by simply altering/ tuning the placement or positioning of the ballistic ceramic tiles in its cellular structure during production in the laboratory by powder metallurgy process. For instance, if the desired properties of the composite are high structural strength/weight ratio and modulus of elasticity, carefully aligning the ceramic aggregates in a regular pattern followed by a controlled foaming of the aluminum alloy powder will more likely produce stiffer composites with these excellent features. However, where the sought-after property is high energy absorption capacity/efficiency, more like those of conventional foams, random orientation of the ballistic tiles is more favoured. Therefore, it is now more possible to design aluminum foam composite to exhibit multifunctional properties that is, while a section of the composite could be made with high stiffness and strength to adapt to load bearing and impact, another section of the same composite could be configured to enhance its absorption/dissipation potentials.

\subsection{Application of Digital Image Correlation (DIC) in Compression Test of Metallic Foams}

The results from this research have shown that DIC could be utilised in uniaxial compression test of metal foams notwithstanding the porosity of their surfaces (outer skin). However, this application is only limited to the elastic stage of the compression test and does not give accurate data in the plateau and densification region of the stress-strain failure curve of trial steel foams and aluminum foam ceramic composites. It is pertinent to state that the accuracy of results obtained in the elastic region could be extended into the plateau stage (that is, up to $25 \%$ compression strain) if the rate of loading of the cross-head displacement is lowered to $0.5 \mathrm{~mm} / \mathrm{min}$, leading to a reduction in the vibration experienced during the experiment, which 
affects, in general, the level of accuracy of data collected by the acquisition system of DIC. In addition to the usefulness of DIC in the linear elastic stage (that is, within $7 \%$ strain) of a quasi-static compression test experiment, it could also be used to study the mode of failure of metallic foams (and composites) in a compression test experiment from zero strain to the final densification stage.

\section{CONCLUSIONS AND RECOMMENDATION 4.1 Conclusions}

This research work has created two distinct types of composites made through the combination of aluminum alloy powder and recycled ballistic ceramic aggregates by metallurgy process. The mechanical properties of these novel materials under compression load were determined and compared to those of trial steel foams in this research and baselines of previous researches. The following conclusions are drawn from the results observed in this study;

i) It is possible to determine the mechanical properties of aluminum foam ceramic composites and steel foams with a good degree of accuracy in their linear elastic stages when using DIC in a compression test experiment, but such level of accuracy is not guaranteed in their plateau and densification regions.

ii) The accuracy of data obtained from the data acquisition software of DIC is affected by the rate of loading of the cross-head displacement of the compression machine. The slower the rate of loading, the higher the level of accuracy, which is as a result of a drop in the degree of vibration of the specimens tested.

iii) The orientation of ceramic aggregates in the cellular structure of aluminum foam composites affects their mechanical properties in compression. A regular orientation gives a stiffer and stronger composite than a random orientation which mimics the behaviour of a typical metal foam.

iv) Recycled ceramic inclusions to aluminum foam in regular/structured pattern increases its strength/density ratio, plateau stress, yield stress and relative density, but decreases its modulus of elasticity, while in random/irregular pattern increases its strength/density ratio, plateau stress and relative density, but decreases its yield stress and modulus of elasticity.

\subsection{Recommendation}

Further research is required in order to fully understand the mechanical properties of these novel materials in tension, torsion and shear, as well as a field test to verify their abilities in providing adequate resistance to forcible entry threats. In addition, extensive research is recommended to determine their application in the design of structural elements with excellent shield against harmful radiations such as neutron, $x$-rays and gamma rays.

\section{REFERENCES}

[1] Marx, J., and Rabiei, A. "Overview of Composite Metal Foams and their Properties and Performance", Advanced Engineering Materials, 2017, pp.1-13.

[2] Sadot, O., Antegy, L., Harush, S., Levintant, O., Nizri, E., Ostraich, B., Schenker, A., Gal, E., Kivity, Y., and BenDor, G. "Mitigation of Blast Effects on Protective Structures", Journal of Structural Engineering, 2005, p.131.

[3] Ramamurty, U., and Paul, A. "Variability in Mechanical Properties of a Metal Foam", Acta Materialia, Vol. 52, 2004, pp.869-876.

[4] Neville, B.P., and Rabiei, A. "Composite metal Foams Processed through Powder Metallurgy", Materials and Design, Vol. 29, 2008, pp.388-396.

[5] Rabiei, A., Neville, B., Reese, N., and Vendra, L. "Composite Metal Foams under Compressive Cyclic Loadings", Material Science Forum, 2007, pp.539-543.

[6] Orbulov, I.N., Katona, B., and Szebenyi, G. 2014. "Fatigue Properties of Metal Matrix Syntactic Foams", International Congress Center Dresden, Germany, Cellular Materials-Cellmat, 2014.

[7] Mondal, D.P., Das, S., Ramakrishan, N., and Uday Bhasker, K. 2009. "Cenosphere Filled Aluminum Syntactic Foam made through Stir-Casting technique", Composite: Part A, 40, pp.279-288.

[8] Wu, G.H., Dou, Z.Y., Sun, D.L., Jiang, L.T., Ding, B.S., and He, B.F. "Compression Behaviours of CenospherePure Aluminum Syntactic Foams", Scripta Materialia, Vol. 56, 2007, pp.221-224.

[9] Salmon, C.G., Johnson, J.E., and Malhas, F.A. Steel Structures Design and Behaviour: Emphasising Load and Resistance Factor Design, $5^{\text {th }}$ ed, Pearson Prentice Hall, New Jersey, 2009.

[10] Fraunhofer Institute of Manufacturing and Advanced Materials (IFAM). "Foaminal-Properties, Overview and Design Guideline". https://www.ifam.fraunhofer.de. Accessed June 26, 2017.

[11] Xia, X., Chen, X., Zhang, Z., Chen, X., Zhao, W., Liao, B., and Hur, B."Compressive Properties of Closed-Cell Aluminum Foams with Different Content of Ceramic Microspheres", Materials and Design, Vol. 56, 2014, pp. 353-358.

[12] Xia, X., Feng, H., Zhang, X., and Zhao, W. "The Compressive Properties of Closed-Cell Aluminum Foams with Different Mn Additions", Materials and Design, Vol. 51, 2013, pp. 797-802. 